\title{
Chinese Concept Stocks Return, Choose IPO or Backdoor Listing? _ Case Analysis Based on Qihoo 360
}

\author{
Zheming Lu, Qingfan $\mathrm{Hu}$,Xiao Wan,Manlian $\mathrm{Yu}$ \\ Nanjing University of Science and Technology,Nanjing,China \\ Email:624022303@qq.com
}

\begin{abstract}
Since 2010, US stocks have began to short Chinese concept stocks, many Chinese concept stocks have chosen to privatize and return to A shares. In July 2016, Qihoo of Beijing science and Technology Co Ltd completed the privatization transactions, and then it chose IPO directly rather than backdoor listing, and this sparked a hot debate. In this paper, we analyze the case of Qihoo 360 and hope to provide some references for the future listing of Chinese concept stocks. And we hope to take this opportunity to promote the further development and improvement of the domestic market.
\end{abstract}

Keywords: Chinese concept stocks, IPO, backdoor listing

\section{Introduction}

Since 2010, US stocks on the market have began to short Chinese concept stocks. As a result, the price of a lot of Chinese concept stocks which listed in foreign countries fell sharply. In this context, many Chinese concept stocks have chosen privatization, and then return to A shares. On July 15, 2016, Qihoo 360 Technology Co., Ltd. announced that the privatization of the transaction is completed, its stock is no longer publicly traded on the US NYSE. Since then, it has caused a widespread concern about the way of Qihoo 360's returning to A shares. Until March 2017, its trip to return to the A shares has been operating for more than one year.

Before this, more than 600 enterprises have chosen IPO listing and they are lining up, and IPO listing is very crowded. And previously, many Chinese concept stocks,such as Giant network, Focus Media and so on, came back to A shares and they chose a relatively quick way _ backdoor listing. So the market also expected Qihoo 360 would choose the way of backdoor listing, and then repeatedly hype the so-called 360 backdoor concept stocks. However, the latest announcement of the official website of Tianjin Securities Regulatory Bureau showed that on March 23, Huatai United Securities have signed an initial public offering and listed counseling agreement with the Qihoo 360 Technology Co.. It means that eventually the returnee Qihoo 360 chose IPO listing directly, which made a lot of people stunned. Why the Qihoo 360 chose IPO listing rather than backdoor listing when everyone thought it would choose backdoor listing? Why Chinese concept stocks before Qihoo 360 have all chosen backdoor listing? Is there any effect of Qihoo 360's IPO listing on the future return of Chinese concept stocks? What measures should be taken by the State accordingly? This article analyzes the case of the Qihoo 360's selection on IPO listing rather than backdoor listing of A shares. And we hope to provide some references for the future selection of the Chinese concept stocks listing, and then promote the improvement and development of the domestic market.

\section{Analysis of the Way of Listing}

For non-listed companies, the current mainstream way of listing inland is IPO. However,due to the high threshold and long cycle of IPO, many non-listed companies discouraged. To a certain extent, the emergence of backdoor listing provide non-listed companies a new way to list. For the Chinese concept stocks which have completed the privatization, they have spent a lot of cost of time to complete privatization transactions and delist. So it is no doubt imminent for them to return to A shares, and it is also very important to choose which way to list. 


\subsection{IPO}

IPO is the initial public offering, refers to an enterprise or a company (stock limited company) sells its shares to the public for the first time. The requirements of IPO in China are strict and the scrutiny is also strict. Specifically, the requirements are as follows: (1) The issue of stocks has been approved by the securities administration department of the State Council. (2) The total share capital of the company is not less than RMB 30 million. (3) The number of public offering shares accounts for more than $25 \%$ of the total number of shares. (4)The proportion of public offering should be more than $10 \%$ if the total share capital is more than 400 million yuan. (5) The company do not have major violations in three years, and its financial and accounting reports do not have false records.

After the incorporated company owns the conditions of listing, it only owns the eligibility to apply for listing. And if it wants to become a true listed company, it must also apply under the legal procedures, and then it can list after the relevant review and approval. It takes about 18 months to 24 months from the preparation of the feasibility report to pass the check.

\subsection{Backdoor Listing}

Backdoor listing, as the name suggests, it is an unlisted business to achieve the purpose of listing with the body. The shell here usually refers to some of the listed companies with lower market value. Unlisted companies inject the capital into such companies, and get the control of the company, and use such a way to make their parent company list.

To achieve the backdoor listing, company must combine its own business conditions, asset conditions, financing capacity and development plans to choose a shell company with appropriate size. The shell company should have a certain quality, should not have too much debt and bad debts, and should have a certain profitability and restructuring of the plasticity. Next, through mergers and acquisitions, non-listed company obtain a relative holding position, and it should consider the shell company's share capital structure. As long as the company reaches its holding position, it success.

\section{Case Analysis}

Qihoo of Beijing science and Technology Co Ltd (hereinafter referred to as Qihoo 360) is a leading supplier which produces Internet and mobile security products and provide service in China. According to third-party statistics, 360 is one of China's top three Internet companies according to the number of users. It was founded in September 2005, it is China's leading Internet security software and Internet services company. On March 30, 2011, Qihoo 360 officially listed on the New York Stock Exchange.

\subsection{Case Background}

On December 2015, Qihoo 360 announced that it has gotten a final privatization agreement with the investor alliance, which would acquire Qihoo 360 for about \$ 9.3 billion in cash. The deal became the largest privatized deal in Chinese companies which listed in America.

On July 15, 2016, Qihoo 360 announced that the privatization transaction have completed, its stock was no longer publicly traded on the US NYSE. Since then it has caused widespread concern on the way for Qihoo 360 to return to A shares. The market is more inclined to IPO or backdoor listing for the returning. Its returning to A shares has been running for more than a year since March 2017.

\subsection{Reasons of the delisting of Qihoo 360}

Different from the private delisting of the state-owned enterprises in the capital market, the delisting of Chinese concept stocks have obvious economic motives. Some of the businesses delist because the stock price is downturn, they can not achieve refinancing and are forced to withdraw from the market. Some companies are returning to the domestic capital market because of the strategy adjustment. There are two reasons for Qihoo 360 to delist.

On the one hand, after the rally of the share price of Qihoo 360 in 2013, it hit to the highest valuation of \$120.79 in March 2014 since the IPO. However,before the day of announcement of privatization news, 360 shares closed at just $\$ 66.05$. One of the important reason for the privatization of 360 was that the value was underestimated by the US capital market. In June 2015, in Hongyi Zhou's internal 
letter, he said that privatization was the prudent decision after 360 repeatedly consider the current global and China capital market environment. And the current $\$ 8$ billion market value of 360 did not fully reflect the value of 360 .

On the other hand, with the gradual growth of the domestic market and the continuous improvement of the comprehensive influence, the attraction of investing in A-share market significantly enhanced. A-share market has a strong profit effect. In particular, the intensity of repeated bursts of new shares is enough to significantly enhance the overall valuation of listed companies. The needs of corporate financing and refinancing have been greatly improved. In recent years, market speculation on the concept of speculation almost reached the maximum.

\subsection{Analysis of 360 Listing}

For the science and technology company of 360, there have been news said that Shanghai and Shenzhen, the two exchanges have paid attention to 360 and sent the Commissioner to visit it. But 360 has not revealed the intention to choose which market.

In general, 360 can choose to queue up and backdoor at the same time. The market previously speculated that 360 would choose backdoor listing, but the final results showed that 360 chose the way of IPO. We analyze the reasons from three aspects for 360 to choose IPO.

First of all, from the perspective of the country, in June 2016, the State Council executive meeting proposed that 'Promoting special equity structure venture enterprises listing in the territory'. It is expected to break the return system and policy constraints of the current Chinese concept stocks to return, and it released the signal of encouraging the return of Chinese concept stocks. According to the relevant report, the China Securities Regulatory Commission is considering to provide fast access to the IPO for the large technology companies such as Qihoo 360, Ant Financial Services Group and so on. Coupled with the accelerated approval of the domestic listing, it is normal for 360 to choose IPO rather than Backdoor list.

Secondly, the risk of backdoor listing is large. Since the second half of 2016, for the phenomenon of speculating 'shell', the Commission issued many kinds of stringent new regulations, and improved the relevant supporting regulatory measures. From the cancellation of the reorganization of the listed financing, to improve the requirements of the strength of the reorganization, and then to extend the stock lock-in period of relevant shareholders, they all showed the government's determination in reducing the short-term speculation and concept hype. At the same time, the new regulations also strengthened the responsibility of listed companies and intermediaries, and increased accountability, which broken the dreams of some companies to rapidly list and encircle money. In the current situation, the risk of backdoor listing is large because of the risk of regulatory level and the unhealthy shell. The shell may have debt risks in potential. 360 did not have the risk of backdoor to choose IPO. Lastly, most previous Chinese concept companies chose backdoor listing to return mainly because the queuing time of IPO is too long. As a result, the cost of IPO increased. While since last year, A-share checking and issuing have both been speed up, so that IPO is normal gradually. The cost of listing has been significantly reduced. As a result, backdoor listing is no longer a helpless choice for listing. For the security field of 360 which owned the attention of our country, the state will provide special policy to accelerate its listing speed in its IPO process, especially in the process of queuing.

\subsection{The Influence of the choice of 360}

In recent years, many Chinese enterprises which listed oversea have privatized, and then return to A shares. Because of the rigorous audit procedures and long queuing time of A shares, many companies thought that their time costs have been depleted. Enterprises seek ways to reduce the cost of listing, and then the backdoor listing has become the best option for enterprises to list quickly, which directly led to the phenomenon of A-share market backdoor blowout. In 2015, only one year, the number of the reorganizations of major assets whose purposes are the backdoor listing was up to 79. The behavior of Focus media backdoor Qixi Holdings, Shen Tong Express backdoor Aidi Xi, Giant Network Backdoor Century Cruise has become the template. However, due to the shortage of the shell 
in the market, shell have become the goal for many company to chase. And many uneasy goodwill advocated backdoor to gain profit, resulting in the chaos of the market.

It seems that under the positive guidance of the relevant policies in the country, it is not surprise for 360 to choose to line up to list. Especially in today's capital market, 360's move is known as a 'stream' and an 'antivirus'. Since the announcement of the normal process of IPO of 360, many shell stocks began to plunge. According to Dongcai data, it showed that, on March 20, ST concept stocks fell $2.02 \%$, Shell Resources Concept shares fell $2.57 \%$, while the broader market fell only $0.96 \%$. Obviously, 360 has become the last straw to overwhelm the market chaos and a new example of the Chinese concept stocks to return.

\section{Conclusions and Revelation}

Since 2015, the wave of the privatization and the return of Chinese concept stocks has been accelerated. The choice of 360 to IPO list is undoubtedly opened a new door for the Chinese concept stocks. Upon to the current situation, the China Securities Regulatory Commission do not have too much demand on the profitability of IPO business. Recently, net profit of businesses which are approved to list is about 20 million yuan. And the listing threshold is not too high for the Chinese concept stocks abroad. The backdoor is not without the threshold, backdoor and IPO do not have many differences in fact. It needs companies earn profits in the past three years, meet a criterion of IPO and own enough cash flow. These are rigid indicators. Even if companies such as the Focus Media, also suffered defeat in the backdoor problem, and it succeed in the second time.

After the completion of privatization and other preparatory work, Chinese concept stocks need to reference successful experience and combine with it own characteristics and market conditions to choose what way to land A shares. In particular, the current Chinese capital market is implementing a series of reforms, and this requires listing companies to make a choice according to the future market environment. The selection of 360 provides the return of the stocks a reference.

For the A-share market, the return of high-quality stocks is conducive to enhancing the competitiveness of the market and enhancing the attractiveness of the entire market investment. In recent years, the trend of returning stocks is overwhelming. In the face of A-share market with more than 3,000 listed companies, the state not only need to actively guide the return of high-quality enterprises and provide fast IPO listing channels for high-quality companies at the right time, the state but also need to make great efforts on the delisting, and should not make A shares to be a tool for the financing of listed companies.

\section{References}

[1] Zaiquan Wang, A Brief Analysis of the Performance and Causes of Stocks in the US Stock Market. Business Age, 64-65(2003).

[2] Siqing Song, Qiao Ceng, An Analysis of the Privatization of Chinese Concept Stocks. Chinese Market,2016(20).

[3] Zexiang Shao, A Probe into the Problem of Privatization_ Case Analysis on Poly Beauty Products. Chinese Market, 2015(04).

[4] Jigao Zhu, Yang Duan, Xin Li,Zaiquan Wang, A Brief Analysis of the Performance and Causes of Stocks in the US Stock Market. Business age, 64-65(2003).

[5] Siqing Song, Qiao Ceng, Research on Privatization of Stock and Its Economic Consequences. Financial Research, 2015(04).

[6] Jensen M C, The Eclipse of the Public Corporation[J].Harvard Business Review, 61-74(1989). 